JURNAL PENDIDIKAN USIA DINI

DOI: https://doi.org/10.21009/JPUD.122

DOI: https://doi.org/10.21009/JPUD.122.07

\title{
MODEL ALAT BANTU LATIHAN (HAND PADDLE) UNTUK PERENANG USIA DINI
}

\author{
Ika Novitaria Marani' ${ }^{1}$; Heru Miftakhudin² \\ Program Studi Pendidikan Olah Raga, Universitas Negeri Jakarta, Indonesia

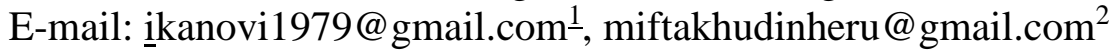

\begin{abstract}
ABSTRAK
This study aims to develop a model of exercise aids (hand paddle) as a training medium to train finger density in early swimmers. The research method used is the Sugiyono's model of research and development method. Hand paddle modification was developed through a small-scale trial of 29 early swimmers from 3 swimming associations in East Jakarta. Small-scale trials were conducted using the pre-posttest design experiment with 6 training sessions using paddle modification. The results of the research and product development showed that (1) the media of exercise aids (hand paddle) significantly increased the density of the fingers in early childhood (2) the validity of exercise aid media indicated by the results of $87 \%$ swimming expert validity with the category very feasible and the validity of $75 \%$ biomechanics experts with appropriate categories, (3) The effectiveness of hand paddle media indicated by the results of the pretest and posttest, obtained tcount $=6.71>$ t table -2.06 , with sig (2 tailed) and degrees of freedom) 05
\end{abstract}

Keyword: Hand paddle, swimming, early age

Penelitian ini memiliki tujuan untuk mengembangkan model alat bantu latihan (hand paddle) sebagai media latihan melatih kerapatan jari tangan pada perenang usia dini. Metode penelitian yang digunakan adalah metode penelitian dan pengembangan ( $R$ \& D) model Sugiyono. Modifikasi hand paddle dikembangkan melalui uji coba skala kecil terhadap 29 perenang usia dini dari 3 perkumpulan renang di Jakarta Timur. Uji coba skala kecil dilakukan dengan menggunakan eksperimen pre-posttest design dengan 6 kali sesi latihan menggunakan paddle modifikasi. Hasil penelitian dan pengembangan produk yang dihasilkan menunjukkan bahwa (1) Media alat bantu latihan (hand paddle) signifikan meningkatkan kerapatan jari - jari tangan pada anak usia dini (2) Kevalidan media alat bantu latihan yang ditunjukkan oleh hasil validitas ahli renang $87 \%$ dengan kategori sangat layak dan validitas ahli biomekanika 75\% dengan kategori layak, (3) Keefektifan media alat bantu (hand paddle) yang ditunjukkan oleh hasil pretest dan posttest, diperoleh thitung $=$ $6.71>$ ttabel -2.06 , dengan sig (2 tailed) dan derajat kebebasan 0.05 .

Kata Kunci: Hand paddle, Latihan Renang, Usia Dini

\section{PENDAHULUAN}

Renang merupakan salah satu cabang olahraga yang berpotensi memperoleh medali terbanyak dalam suatu multi event. Untuk mendapatkan prestasi yang maksimal diperlukan beberapa aspek, yaitu teknik, taktik, mental dan fisik. Faktor-faktor pendukung yang menentukan prestasi atlet tersebut, harus dimanfaatkan seefektif mungkin dan diusahakan agar terus ditingkatkan. Dan selama berapa decade terakhir, kinerja renang telah dipelajari dengan perspektif yang 
berbeda. Hal ini dibuktikan pada beberapa penelitian yang berusahan untuk menjelaskan tentang pengaruh kinematic pada kinerja renang serta hubungan mereka dengan jarak kompetisi yang berbeda (Keskinen \& PV Komi, 1993; Arellano, Brown, Cappaert, \& Nelson, 1994). Untuk dapat meningkatkan prestasi, maka perlu dilakukan sistem pembinaan olahraga dengan memperhatikan nilai-nilai, kebiasaan dan kekhasan cabang olahraga renang, terutama bagi atlet-atlet muda. Oleh karena itu, perlu dilakukan pengenalan olahraga renang sudah dapat dimulai dari usia anak-anak. Bompa (2000, h. 35)mengatakan bahwa usia untuk belajar renang yang ideal dimulai dari usia 3-7 tahun, untuk usia 10-12 tahun merupakan usia untuk spesialisasi, dan usia 16-18 tahun merupakan usia prestasi puncak (peak performance). Sebagai dasar bekal pembinaan olahraga, maka anak-anak usia dini harus mengembangkan dasar-dasar keterampilan terutama berkaitan dengan teknik secara umum.

Dalam melakukan proses latihan, terdapat faktor pendukung dan faktor penghambat. Adapun beberapa kendala yang sering dihadapi dalam latihan renang terutama pada anakanak, yaitu: mempertahankan posisi mengapung dengan benar, rneluncur dengan posisi yang benar (streamline), melakukan pemapasan di air, dan secara keseluruhan adalah bagaimana menguasai teknik gaya tertentu dengan efisien dan efektif (Sugiyanto, 2011). Hal ini juga didukung oleh studi pendahuluan yang dilakukan melalui wawancara yang dilakukan peneliti kepada beberapa pelatih perenang usia dini/pemula di beberapa klub renang di Jakarta, ditemukan fakta bahwa masih banyak perenang usia dini/pemula yang melakukan kesalahan teknik dasar.

Untuk memperbaiki kesalahan teknik dasar dan akhirnya meningkatkan performance, maka beberapa tahun terakhir pelatih menggunakan bantuan peralatan dalam latihan renang. Penggunaan peralatan tersebut digunakan untuk membantu meningkatkan kinerja agar stroke lebih efisien. Beberapa penelitian telah mengevaluasi perubahan potensial bahwa tambahan alat seperti parasut atau hand paddle dapat membuat peningkatan kinerja renang seorang atlet. Seperti penelitian yang dilakukan oleh Matos, 2012, dengan judul: "The use of hand paddles and fins in front crawl: biomechanical and physiological responses". Hasil penelitian menunjukkan bahwa alat bantu Paddles dan fins yang digunakan selama latihan berenang sebagai alat bantu latihan dapat meningkatkan kinerja dalam renang. Karena penggunaan peralatan ini dapat mengubah parameter fisiologis dan kinematika renang.

Penelitian yang dilakukan oleh Telles et al., (2016), yang berjudul: Effect of hand paddles and parachute on backstroke coordination and stroke parameters menunjukkan bahwa penggunaan hand paddles dan parasut dapat meningkatkan dan mengurangi stroke length. Selain itu, terjadi peningkatan durasi fase dorongan ketika dayung tangan digunakan. Hal ini menunjukkan bahwa penggunaan hand paddle tidak hanya memberikan peningkatan kekuatan dan kinerja aerobic, tetapi juga dapat memiliki efek pada kinematika renang. Hal ini disebabkan oleh permukaan yang mendorong, sehingga penggunaan hand 
paddle cenderung dapat meningkatkan kecepatan dan panjang stroke.

Salah satu kesalahan yang banyak dilakukan oleh perenang usia dini/pemula adalah terbukanya atau kurang rapatnya jari-jari tangan pada saat melakukan teknik kayuhan dalam berenang. Sementara itu, pelatih mengaku terkadang kesulitan dalam mengedukasi perenang usia dini/pemula untuk merapatkan jarijari mereka selama melakukan kayuhan dalam berenang. Jika ditinjau dari ilmu biomekanika dalam renang, kerapatan jari-jari tangan dapat berpengaruh terhadap daya dorong (propulsive force) ketika berenang. Ketika berenang, seorang perenang melakukan kayuhan dengan menggunakan tangannya. Pada saat melakukan kayuhan (paddling), seorang perenang mendorong air ke arah bagian belakang tubuh dan pada saat tersebutlah muncul jenis hambatan drag force yang bekerja berlawanan dengan arah gerak tubuh (Colwin, 2002).

Penelitian mengenai efek posisi jari-jari tangan terhadap hambatan dan daya dorong pada saat berenang terus dilakukan oleh ilmuwan di bidang olahraga spesialisasi cabang olahraga renang. Marinho, Barbosa, \& Al (2010), mengadakan penelitian mengenai efek pemisahan jari-jari tangan terhadap daya dorong pada saat berenang. Penelitian tersebut menyimpulkan bahwa posisi jari-jari tangan dengan jarak 0,32 cm menghasilkan koefisien drag force paling besar. Penelitian di atas telah membuktikan bahwa posisi jari-jari tangan memberikan pengaruh yang cukup signifikan dalam menghasilkan daya dorong pada saat seseorang berenang. Jika kembali kepada teori biomekanika, pada dasarnya, agar seorang perenang dapat berenang dengan cepat, maka perenang harus selalu berusaha: Mengurangi atau memperkecil hambatan dan memperbesar daya dorongnya.

Apabila seorang perenang berenang dengan posisi jari-jari tangan terbuka, maka secara otomatis luas penampang telapak tangan untuk melakukan kayuhan menjadi lebih kecil. Padahal semakin besar area tangan pada saat melakukan kayuhan, maka semakin besar pula hambatan (drag force) yang dihasilkan, dan semakin besar pula daya dorong (propulsive force) yang dihasilkan. Apabila daya dorong yang dihasilkan relatif kecil, tentunya seorang perenang tidak dapat berenang dengan cepat. Padahal kecepatan merupakan tolok ukur utama prestasi dalam cabang olahraga renang.

Oleh karena itu diperlukan alat bantu yaitu hand paddle untuk melatih posisi jari-jari tangan agar rapat sehingga dapat lebih mengoptimalkan hasil renangan. Hand paddle yang ada saat ini terlalu besar bagi anak-anak, sehingga anakanak merasa berat apabila melatih posisi jari - jari tangan dengan menggunakan model hand paddle yang saat ini sudah banyak digunakan. Berdasarkan pada penjabaran permasalahan berdasarkan hasil penelitian di atas, maka perenang usia dini/pemula masih banyak melakukan kayuhan dengan jari-jari tangan terbuka, maka perlu ditemukan solusi untuk mengedukasi perenang agar dapat melakukan teknik kayuhan usia dini yang benar. Sehingga, diharapkan dengan adanya pengembangan model yang dibuat dapat memberikan solusi 
kepada perenang usia dini/pemula agar mampu berenang dengan teknik yang benar dan mampu meraih prestasi yang baik pula.

\section{KAJIAN TEORITIK}

\section{Hakikat Renang}

Renang merupakan olahraga yang mengadu kecepatan atlet renang dalam berenang di air. Gaya renang yang dipertandingkan adalah gaya bebas, gaya kupu-kupu, gaya punggung, dan gaya dada. Perenang yang memenangkan pertandingan renang adalah perenang yang dapat menyelesaikan jarak dengan waktu tercepat. Di dalam gerakan-gerakan tersebut terdapat dasar-dasar mekanika yang berlaku (Colwin, 2002), yaitu: Hambatan dan dorongan, Teori hukum kuadrat dan Kemampuan mengapung.

Secara sederhana pada saat seseorang melakukan gerakan dalam air ada dua kekuatan yang saling berlawanan yaitu kekuatan yang menghalangi gerakan yang disebut hambatan dan kekuatan yang menyebabkan seseorang dapat bergerak yang disebut dorongan. Hambatan disebabkan oleh dorongan balik dari air di depannya yang didesak atau dipindahkan, sedangkan dorongan dihasilkan dari gerakan tangan dan kaki. Sehingga dapat disimpulkan bahwa cepat atau lambatnya gerakan ke depan dalam renang merupakan hasil yang diperoleh dari selisih antara besarnya daya dorong dengan hambatannya, sehingga semakin kecil hambatan dan semakin besar dorong akan menyebabkan laju gerakan yang lebih cepat begitu pula sebaliknya.
Gerakan tangan yang melakukan tekanan kepada air, secara otomatis akan menyebabkan terjadinya kontraksi otot-otot ekstensi pada bahu sehingga bentuk tangan atau ukuran tangan dapat mempengaruhi besarnya lift dan drag force secara umum sehingga bentuk tangan yang semakin besar akan mempengaruhi daya dorong secara maksimal. Selain itu hal yang menyebabkan dorongan dalam berenang adalah gerakan tangan dan kaki yang dilakukan perenang sehingga air terdorong kebelakang. hal ini sesuai dengan hukum aksi reaksi (Adrian \& Cooper., 1995).

Soejoko Hendromatono (1992) menerangkan salah satu hasil penelitian dari Counsilman mengenai 5 teknik posisi tangan:

1. Tangan datar, jari-jari rapat dengan ibu jari

2. Tangan datar, jari-jari rapat, dengan ibu jari terbuka

3. Tangan datar, semua jari terbuka

4. Tangan dilikukan (cupped), dan jari-jari rapat

5. Tangan datar, pergelangan tangan dan jari-jari sedikit di lekuk keluar

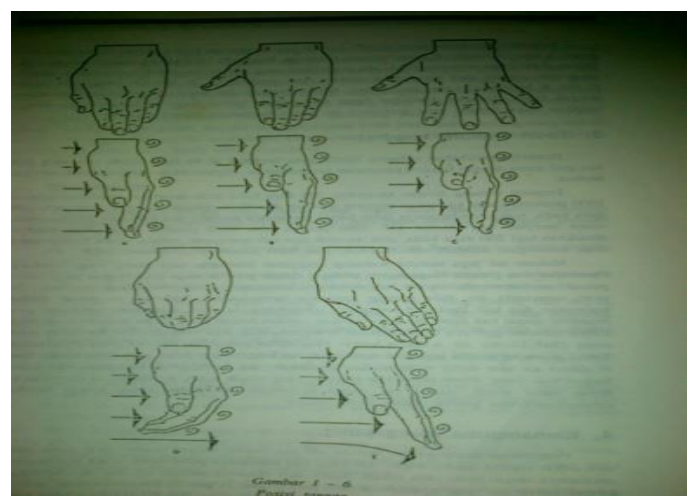

Gambar 1. Lima teknik posisi tangan

Sumber: Counsilman dalam

(Soejoko Hendromartono,1992 p.8) 


\section{Hakikat Media Latihan}

Media sebagai komponen strategi pembelajaran merupakan wadah dari pesan yang oleh sumber atau penyalurnya ingin diteruskan kepada sasaran atau penerima pesan tersebut, dan materi yang ingin disampaikan adalah pesan pembelajaran, dan bahwa tujuan yang ingin dicapai adalah terjadinya proses belajar (Trianto, 2009). Media adalah segala sesuatu yang dapat digunakan untuk menyalurkan pesan dari pengirim ke penerima sehingga dapat merangsang pikiran, perasaan, perhatian dan minat serta perhatian siswa sedemikian rupa sehingga proses belajar terjadi (Sadiman., R, \& Haryono., 1996). Sehingga, kesimpulan dari media adalah pesan secara langsung ataupun tidak langsung yang disampaikan kepada penerima pesan dalam bentuk keterampilan, pengetahuan, ataupun sikap dan diharapkan siswa atau penerima informasi mendapatkan rangsangan informasi yang didapat.

Thomson dalam Ambarukmi
(2007) secara sederhana mendefiniskan latihan (training) sebagai "proses sistematis untuk meningkatkan kebugaran atlet sesuai cabang olahraga yang dipilih". Sebelumnya, Hare (dalam Ambarukmi, 2007) menyatakan bahwa latihan adalah "proses penyempurnaan berolahraga melalui pendekatan ilmiah, khususnya prinsip-prinsip pendidikan, secara teratur dan terencana sehingga mempertinggi kemampuan dan kesiapan olahragawan”. Berdasarkan dua definisi diatas, dapat disimpulkan bahwa latihan merupakan sebuah bentuk proses, yang tidak berjalan hanya satu kali saja melainkan suatu sistem yang bertahap.

Begitu juga definisi latihan yang dikemukakan oleh Harsono (1998) yang menyatakan bahwa "latihan adalah proses yang sistematis dari berlatih atau bekerja yang di lakukan secara berulang-ulang dengan kian hari kian menambah jumlah beban latihan atau pekerjaannya". Dalam definisinya tersebut secara jelas disampaikan bahwa latihan merupakan bentuk proses yang berulang-ulang, tidak hanya dilakukan sekali saja. Berdasarkan kesimpulan definisi media dan latihan yang telah dirumuskan oleh peneliti, maka peneliti menarik kesimpulan bahwa media latihan adalah pesan dalam bentuk langsung ataupun tidak langsung yang di sampaikan kepada atlet secara sistematis untuk menyempurnakan kualitas kinerja atlet.

Perenang telah menggunakan hand paddle untuk memperbesar area tangan. Sehingga luas permukaan tangan menjadi faktor yang mempengaruhi kecepatan saat berenang, sehingga banyak orang yang memikirkan cara untuk memperluas area tangan. Dalam memperluas area tangan di butuhkan alat bantu untuk memberikan solusi tersebut dalam hal ini model alat bantu latihan tangan yaitu hand paddle.

\section{METODOLOGI PENELITIAN}

Metodologi yang digunakan dalam penelitian ini adalah penelitian dan pengembangan $(R \& D)$ karena penelitian yang dilakukan untuk menghasilkan produk tertentu, dan menguji keefektifan produk tersebut (Sugiyono, 2011). Rancangan atau 
desain model yang digunakan dalam penelitian dan pengembangan ini adalah rancangan pengembangan yang dikembangkan oleh Sugiyono. Adapun tahapan penelitian yang digunakan dalam penelitian ini adalah: penelitian pendahuluan, perencanaan pengembangan model, validasi, evaluasi, dan revisi model, uji coba kelompok kecil dan revisi model.

\begin{tabular}{lrr}
\multicolumn{1}{c}{ Penelitian } & & pendahuluan \\
dilakukan & untuk & mencari \\
permasalahan & dan & kebutuhan
\end{tabular}
terhadap penggunaan hand paddle pada anak usia dini. Pada tahap perencanaan dan pengembangan model, produk mulai dirancang berdasarakn informasi tentang permasalahan dan kebutuhan penelitian. Pada tahap validasi, evaluasi dan revisi model dilakukan validasi oleh para ahli yang mencermati model yang dikembangkan sesuai dengan tujuan penelitian. Setelah divalidasi, para ahli mengevaluasi rancangan model yang sudah dibuat. Langkah selanjutnya aalah melakukan revisi model berdasarkan hasil validasi dan evaluasi dari para ahli.

Setelah model di revisi, tahap selanjutnya aalah uji coba kelompok kecil. Adapun sasaran penelitian yang digunakan sebanyak 29 perenang (19 laki-laki, 10 perempuan) dari Klub Putra Rama, Bina Taruna, dan Meteor Lintas Aquatic. Uji coba kelompok kecil dilakukan melalui prosedur eksperimen pre-test dan post-test design. Pengukuran dilakukan melalui prosedur pengamatan posisi jari-jari tangan perenang. Prosedur observasi dilakukan dengan menggunakan form ceklis observasi yang disusun berdasarkan penelitian mengenai 5 posisi tangan yang dilakukan Counsilman. Pada setiap sampel penelitian dilakukan observasi posisi jari awal, kemudian melewati 6 sesi latihan menggunakan paddle untuk kemudian dilakukan observasi kembali terhadap posisi jari tangannya pada saat berenang.

\section{HASIL DAN PEMBAHASAN}

Penelitian ini menghasilkan produk media alat bantu latihan (hand paddle) untuk meningkatkan kerapatan jari tangan pada anak usia 7-8 tahun pada perkumpulan renang Jakarta Timur. Tahapan dari penelitian dan pengembangan media alat bantu latihan (hand paddle) meliputi:

\section{Draft 1}

Draft 1 didapat dari hasil pengembangan draft awal yang merupakan draft yang disusun dari hasil analisis kebutuhan dan studi literature. Setelah di dapat draft 1, maka dilakukan validasi ahli. Validasi ahli diperlukan untuk mendapatkan model draft 2.

\section{Draft 2}

Draft 2 merupakan revisi hasil uji coba kelompok kecil dan hasil validitas ahli. Setelah mendapatkan draft 2, dilakukan revisi pengembangan dan menghasilkan model draft 3 .

\section{Draft 3}

Pada pengembangan draft 3 dilakukan uji coba kelompok besar serta hasil dari revisi menjadi draft final yang disiapkan untuk uji efektifitas media. 
Model Alat Bantu Latihan (Hand Paddle)

Novitaria \& Miftakhudin

\section{Draft Final}

Hasil dari pengembangan media alat bantu latihan (hand paddle) menghasilkan draft final untuk kemudian dilakukan uji efektifitas media:

\section{Hasil Kelayakan Model}

Adapun kelayakan model, divalidasi oleh pakar dalam renang dan ahli biomekanika.

\begin{tabular}{cccc}
\multicolumn{3}{l}{ Tabel 1. Persentase } & Validasi Ahli \\
\hline No & Pakar & Persentase & $\begin{array}{c}\text { Keterangan } \\
\text { kelayakan } \\
\text { media }\end{array}$ \\
\hline 1 & Renang & $87 \%$ & $\begin{array}{c}\text { Sangat } \\
\text { Layak }\end{array}$ \\
2 & Biomekanika & $75 \%$ & Layak \\
\hline
\end{tabular}

\section{Uji Empiris}

Uji empiris dilakukan melalui uji coba kelompok kecil, uji coba kelompok besar serta uji efektifitas.

\section{Uji Efektifitas Model Alat Bantu Latihan}

Uji efektifitas bertujuan untuk melihat peningkatan kerapatan jari jari tangan pada anak usia 7-8 tahun dengan menggunakan media alat bantu latihan (hand paddle). Peneliti juga melihat ada tidaknya perbedaan dalam kerapatan jari tangan sebelum dan sesudah menggunakan media alat bantu latihan (hand paddle). Berikut nilai pre-test dan post-test pada uji efektifitas (lihat Tabel 2):
Tabel 2. Hasil uji efektifitas pretest dan posttest

\begin{tabular}{|c|c|c|c|c|}
\hline \multirow{2}{*}{$\begin{array}{l}\mathrm{N} \\
\mathrm{O}\end{array}$} & \multirow{2}{*}{ Resp } & \multicolumn{2}{|c|}{ Posisi Jari Tangan } & \multirow{2}{*}{$\begin{array}{c}\text { Presentasi } \\
\text { Peningkat } \\
\text { an }\end{array}$} \\
\hline & & Sebelum & Sesudah & \\
\hline 1 & R1 & 3 & 5 & $10 \%$ \\
\hline 2 & $\mathrm{R} 2$ & 3 & 5 & $10 \%$ \\
\hline 3 & R3 & 3 & 5 & $10 \%$ \\
\hline 4 & R4 & 3 & 5 & $10 \%$ \\
\hline 5 & R5 & 3 & 5 & $10 \%$ \\
\hline 6 & R6 & 3 & 5 & $10 \%$ \\
\hline 7 & R7 & 4 & 5 & $5 \%$ \\
\hline 8 & R8 & 3 & 5 & $10 \%$ \\
\hline 9 & R9 & 3 & 5 & $10 \%$ \\
\hline 10 & R10 & 4 & 5 & $5 \%$ \\
\hline 11 & R11 & 3 & 5 & $10 \%$ \\
\hline 12 & $\mathrm{R} 12$ & 3 & 3 & $0 \%$ \\
\hline 13 & R13 & 4 & 5 & $5 \%$ \\
\hline 14 & R14 & 4 & 5 & $5 \%$ \\
\hline 15 & $\mathrm{R} 15$ & 3 & 3 & $0 \%$ \\
\hline 16 & R16 & 4 & 5 & $5 \%$ \\
\hline 17 & R17 & 3 & 5 & $10 \%$ \\
\hline 18 & R18 & 4 & 4 & $0 \%$ \\
\hline 19 & R19 & 3 & 5 & $10 \%$ \\
\hline 20 & R20 & 3 & 5 & $10 \%$ \\
\hline 21 & R21 & 4 & 5 & $5 \%$ \\
\hline 22 & R22 & 3 & 4 & $5 \%$ \\
\hline 23 & R23 & 4 & 5 & $5 \%$ \\
\hline 24 & R24 & 3 & 5 & $10 \%$ \\
\hline 25 & R25 & 4 & 5 & $5 \%$ \\
\hline
\end{tabular}

Jika $t_{\text {hitung }}=6,71$ dan $t_{\text {tabel }}=2.06$ maka, 6,71 > 2.06. Hal ini menunjukkan bahwa thitung $>t_{\text {tabel. }}$. Sehingga H0 ditolak, dan artinya H1 diterima. Ini berarti bahwa terdapa perbedaan yang signifikan antara sebelum menggunakan media alat bantu latihan (hand paddle) dan sesudah menggunakan media alat bantu latihan (hand paddle). 


\section{PEMBAHASAN}

Hasil uji coba skala besar menggambarkan bahwa setelah diberikan arahan dan dibantu dengan menggunakan paddle modifikasi, perenang dapat melatih jari-jari nya agar tetap rapat pada saat melakukan kayuhan saat berenang. Sampel penelitian menunjukkan posisi jari tangan yang rapat dengan ibu jari, atau posisi tangan rapat dengan ibu jari masih agak terbuka.

Jika ditinjau kembali dari hukum biomekanika, semakin besar daya dorong yang dihasilkan dari pushing dan paddling dalam renang maka akan semakin besar pula daya dorong yang dihasilkan ke depan. Daya dorong inilah yang kemudian disebut dengan propulsive drag force dalam renang. Oleh karena itu, daya dorong ke belakang yang dihasilkan oleh perenang pada saat paddling dan pushing pun juga harus semakin besar. Salah satu faktor yang dapat meningkatkan daya dorong ke belakang adalah luas permukaan yang semakin besar. Pernyataan ini didukung oleh penelitian yang dilakukan oleh Counsilman, dimana posisi jari tangan yang rapat menghasilkan propulsive drag force lebih besar.

Luas penampang yang besar dalam berenang dapat dihasilkan dari luas permukaan tangan dengan jarijari yang rapat. Hal ini sesuai dengan rumus drag dimana paddling surface (A, dalam $\mathrm{m}^{2}$ ) merupakan komponen penting karena berkontribusi terhadap drag, dimana drag $=(1 / 2$

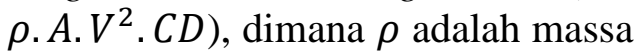
jenis air, $\mathrm{V}$ adalah kecepatan, dan $\mathrm{CD}$ adalah koefisien drag. Dapat terlihat bahwa luas penampang (A) berbanding lurus dengan drag yang dihasilkan. Dengan demikian, jika perenang terbiasa merapatkan jari tangannya pada saat melakukan paddling dan pushing, maka akan semakin besar daya dorong yang dihasilkan. Meskipun demikian, rancangan paddle modifikasi final yang dihasilkan dalam penelitian masih perlu beberapa perbaikan. Secara garis besar tujuan dari pembuatan modifikasi paddle ini tercapai, namun dengan beberapa catatan perbaikan dari segi bahan penyusun paddle ini.

Dalam proses pengembangan model modifikasi paddle mulai dari rancangan paddle tahap pertama hingga tahap final, peneliti mendapatkan beberapa masukan untuk tiap-tiap rancangan paddle modifikasi. Rancangan final yang diperoleh merupakan bentuk paddle modifikasi dengan penampang ringan dan berukuran kecil yang terbuat dari fiberglass. Penampang paddle ini dirancang dengan ukuran yang tidak melapisi seluruh telapak tangan perenang agar perenang tidak merasa terbebani pada saat latihan menggunakan paddle modifikasi ini.

Untuk merapatkan jari tangan sesuai dengan spesifikasi fungsi paddle modifikasi, peneliti menggunakan karet yang melapisi jari tangan perenang. Pada penampang paddle terdapat 4 lubang untuk memasukkan karet. Lubang tersebut terletak di masing-masing ujung kanan dan kiri penampang. Fungsi lubang tersebut adalah untuk memasukkan lubang dan memungkinkan karet untuk dikencangkan atau dilonggarkan sesuai dengan ukuran jari masingmasing anak. 
Model Alat Bantu Latihan (Hand Paddle)

Novitaria \& Miftakhudin

Apabila ditinjau dari segi desain dan bahan, paddle modifikasi final ini memiliki kelebihan dari sisi bahan penampang yang ringan dan tidak membebani perenang pada saat latihan. Selain itu, bentuk karet yang bukan berupa ring yang harus dimasukkan satu persatu juga mempermudah perenang dalam pemakaian paddle modifikasi ini. Meskipun begitu, dari hasil uji coba skala besar masih terdapat beberapa kritik terhadap paddle modifikasi. Salah satu yang masih banyak dikeluhkan oleh sampel perenang adalah ukuran karet yang mereka rasa terlalu tebal, sehingga beberapa terasa mengganjal ketika digunakan.

\section{KESIMPULAN DAN SARAN}

Model hand paddle yang dibuat mampu memberikan perubahan terhadap posisi jari - jari tangan pada anak-anak, karena model hand paddle ini dibuat dengan menyesuaikan luas penampang tangan pada anak-anak. Sehingga, hand paddle itu tidak memberatkan anak-anak ketika digunakan pada saat latihan untuk memperbaiki teknik kayuhan tangan. Adapun saran untuk penelitian ini adalah agar dapat lebih dikembangkan lagi model hand paddle nya dan dibuat produk nya agar bisa dipasarkan dan digunakan bagi anak-anak.

\section{DAFTAR PUSTAKA}

Adrian, M. J., \& Cooper., J. M. (1995). Biomechanics of Human Movement. Iowa: Brown \& Benchmark.

Ambarukmi, D. H. (2007). Pelatihan Fisik Level 1 . Olahraga KEMENPORA, Jakarta.
Arellano, R., Brown, P., Cappaert, J., \& Nelson, R. (1994). Analysis of 50-, $100-$, and 200-m freestyle swimmers at the 1992 Olympic Games. Journal of Applied Biomechanics, 10, 189-199.

Bompa, T. O., \& Carerra, M. C. (2000). Periodization Training for Sports (2nd editio). Champaign: Human Kinetics.

Colwin, C. M. (2002). Breakthrough Swimming. New York, USA: Human Kinetics.

Harsono. (1998). Coaching dan Aspekaspek Psikologis dalam Coaching. Jakarta.

Hendromartono, S. (1992). Olahraga Pilihan Renang I. Jakarta.

Keskinen, K., \& PV Komi. (1993). Stroking Characteristics of Front Crawl SwimmingDuring Exercise. Journal Of Biomechanics, 9, 219226.

Marinho, D. A., Barbosa, T. M., \& Al, E. (2010). Swimming Propulsion Forces Are Enhanced by A Small Finger Spread. Journal of Applied Biomechanics, 87-92.

Matos, C. C. De. (2012). The use of hand paddles and fins in front crawl: biomechanical and physiological responses, (October), 382-392.

Sadiman., A. S., R, R., \& Haryono., A. (1996). Media Pendidikan (Pengertian, Pengembangan, dan Pemanfaatannya). Jakarta: Raja Grafindo Persada.

Sugiyanto, F. X. (2011). Keefektifan Urutan Pembelajaran Keterampilan Gerak Renang. Jurnal Ilmiah Pendidikan, 2(4), 256-266. 
JURNAL PENDIDIKAN USIA DINI

Volume 12 Edisi 2, November 2018

Sugiyono. (2011). Metode Penelitian

parameters,

0414(July).

Kuantitatif, Kualitatif, dan $R \& D$. https://doi.org/10.1080/02640414.2

Bandung: Alfabeta.

016.1201210

Trianto. (2009). Mengembangkan Model Pembelajaran Tematik. Jakarta: Prestasi Puastaka. \& Junior, O. A. (2016). Effect of hand paddles and parachute on backstroke coordination and stroke 